\title{
A TEORIA DA COMPLEXIDADADE E AS ORGANIZAÇÕES
}

\section{The Theory of the Complexity and the Organizations}

Osmar Ponchirolli ${ }^{1}$

\section{Resumo}

O objetivo desse artigo é contribuir para a discussão sobre a importância da teoria da complexidade no estudo das organizações. $\mathrm{O}$ argumento baseia-se na idéia de que ambientes competitivos são aqueles que incentivam a criação de relações não-lineares no processo de gestão que favorece a diversidade, permitindo a geração de maior número de soluções criativas. Procura-se aplicar desenvolvimentos recentes da teoria da complexidade em organizações. Palavras-chave: Paradigma; Sistema vivo; Organização; Complexidade; Aprendizagem complexa e criatividade; Modelos mentais; Estratégia; Adaptação e dinamicidade.

\section{Abstract}

The objective of this article is to contribute for the quarrel on the importance of the theory of the complexity in the study of the organizations. The argument is based on the idea of that surrounding competitive they are those that stimulates the creation of nonlinear relations in the management process that favors the diversity, allowing the generation of bigger number of creative solutions. It is looked to apply recent developments of the theory of the complexity in organizations.

Keywords: Paradigm; Alive system; Organization; Complexity; Complex Learning and mental creativity; Models; Strategy; Adaptation and dinamicidade.

Teólogo, Filósofo, Especialista em Didática do Ensino Superior, Licenciatura plena em Psicologia, História e Sociologia, Mestre e Doutor pela UFSC. É professor do Centro Universitário Franciscano do Paraná - FAE - Business School. e-mail: osmarp@bomjesus.br 


\section{O surgimento de um novo paradigma}

Para Kuhn (1970, p. 175), paradigma é toda uma constelação de opiniões, valores e métodos, participados pelos membros de uma determinada sociedade. Os exemplos de referência, as soluções concretas de problemas, tidas e havidas como exemplares e que substituem as regras explícitas na solução dos demais problemas da ciência normal.

A partir desta definição, fica claro que cada cultura organiza o seu modo de valorar, de interpretar, de interpretar e de intervir na história. A ciência e a técnica são práticas culturais limitadas a uma determinada cultura.

A modernidade trouxe a crença da absolutidade da racionalidade funcional, instrumental. Esta racionalidade influenciou e influencia o comportamento das pessoas e foi definindo a competência como sendo, única e exclusivamente, o domínio das habilidades técnicas.

O diálogo experimental visa compreender e modificar, isto é, conhecer como funciona o universo, a natureza, o comportamento humano e a técnica como operação para modificá-la, adestrá-la e dominá-la. A ciência moderna surge neste contexto.

A nossa dialogação com o mundo organizacional não se faz somente pela via experimental da tecnociência, faz-se também com razão substantiva, onde o diálogo e a busca de apropriação de outras formas de acesso à realidade vão além da racionalidade funcional.

Percebemos o surgimento de um novo paradigma. Está emergindo uma "nova" racionalidade com a totalidade dos seres e de suas relações. Ao afirmar a emergência de um novo paradigma não significa dizer que os dualismos modernos desapareceram. Ainda persistem os dualismos: razão e emoção, mundo material e espiritual, ser humano e organização, ser humano e mundo, feminino e masculino, Deus e mundo, capital e trabalho.

O novo paradigma está sendo gestado. Não nasceu totalmente. Está dando os primeiros sinais de existência. A compreensão da nova racionalidade se observa pelo novo modo de ser, de pensar, de valorar e de agir das pessoas. O conhecer está sendo visto aos poucos como uma forma de entrar em comunhão com as coisas.

Neste contexto, a complexidade, segundo Morin (1980, p. 335-393), é uma nova categoria fundamental na compreensão do novo paradigma. O real é complexo. Densa é a complexidade nos organismos vivos. Eles foram sistemas abertos. Neles se dá o fenômeno da autoprodução e da autoorganização a partir do não equilíbrio dinâmico que busca novas adaptações. Quanto mais próximo ao total equilíbrio, mais próximo está o organismo vivo da sua morte. A distância do equilíbrio, isto é, a situação de caos, cria a possibilidade de uma nova ordem. O caos é generativo e o princípio das organizações de singularidades e de novidades. 
Segundo Prigogine (1996), é pela auto-organização interna que os seres vivos criam estruturas dissipativas da entropia. Os seres vivos trocam energia com o meio, consomem muita energia e por isso aumentam a entropia (desgaste da energia). Produzem entropia e ao mesmo tempo escapam da entropia. Eles metabolizam a desordem e o caos do meio ambiente em ordem e estruturas complexas que se auto-organizam, fugindo à entropia. É por meio da ordem e desordem que a vida se mantém. A desordem obriga a criar novas formas de ordem.

Por três séculos, desde Isaac Newton, os cientistas descreveram o mundo como semelhante a uma máquina. Governando o mundo estavam os princípios de regularidade e ordem. Todas as coisas eram a soma das partes; as causas e efeitos estavam ligados linearmente; e os sistemas moviam-se de modo determinístico e previsível. É claro que os cientistas desde longo tempo estavam atentos para os fenômenos que contradiziam a lógica linear: as formas espirais das chamas de fogo, os redemoinhos em correntes e as formações de nuvens, por exemplo, não podiam ser representadas por simples equações lineares.

O desenvolvimento da teoria do caos nos anos 70 e 80 sugeriu um modelo muito diferente para a maneira como as coisas ocorrem. O mais importante avanço das últimas décadas do século 20 foi a percepção de que o mundo é fundamentalmente não-linear.

Parte do que se tornou a ampla ciência da dinâmica não-linear, ou teoria da complexidade, ligando disciplinas tão diversas quanto física, biologia, química, economia e sociologia, o caos designa áreas de "instabilidade de fronteira" como entidades que se movem entre o equilíbrio de um lado e a completa situação randômica de outro. Nesta área apenas o comportamento criativo ocorre. Chamas e formações de nuvens são sistemas caóticos clássicos: operando longe do equilíbrio, eles são imprevisíveis e ricamente criativos em detalhes, apesar de restritos dentro de certos limites físicos.

Em sistemas caóticos não lineares, as ligações entre causa e feito desaparecem pela amplificação de feedbacks que podem transformar fracas variações iniciais em severas conseqüências. O futuro de tais sistemas não é passível de ser conhecido.

Ficou logo claro para alguns pensadores das ciências sociais que a teoria do caos e da complexidade lançaria muita luz sobre as organizações humanas como companhias, mercados, economias e ecologia. Essas organizações também eram sistemas complexos constituídos por muitos agentes interativos com uma tendência aparente para a auto-organização - pessoas nos mercados, pássaros em bandos, embriões em células, simplicidade na complexidade. E diferentemente das chamas e nuvens elas eram adaptativas, de modo que as regras de seu comportamento mudavam à medida que elas evoluíam e aprendiam. 
Este mundo não é aquele representado pela metáfora de uma máquina. As coisas são mais do que a soma de suas partes; equilíbrio é morte; causas são efeitos e efeitos são causas; desordem e paradoxo estão em toda parte.

Portanto, a complexidade nos organismos vivos se mostra pela presença do princípio Hologramático que neles atua, isto é, nas partes está presente toda a informação do todo. Para se compreender a complexidade, formulou-se a teoria da cibernética e dos sistemas (abertos e fechados). Por ela se procura captar a interdependência de todos os elementos e sua funcionalidade global. Isso constitui dimensões dos fenômenos organizacionais.

Destaca-se neste artigo a teoria da complexidade e as organizações; a complexidade nos sistemas empresariais; a emergência da estratégia a uma nova gestão das organizações e a necessidade de um novo modelo mental.

\section{A teoria da complexidade e as organizações}

O estudo das organizações como sistemas dinâmicos complexos é até de forma um pouco surpreendente a linha de pesquisa que mais tem avançado no campo das ciências humanas. Stacey (1996, p. 19), por exemplo, parte da conceituação de ciência da complexidade como:

O estudo de sistemas que são constituídos por uma grande quantidade de agentes que integram entre si para produzir estratégias adaptativas de sobrevivência para eles próprios, e, portanto, para o sistema como um todo, ou partes do sistema aos quais eles pertencem. Esse sistema, por sua vez, interage com outros sistemas, formando um supra-sistema no qual eles são agentes que co-envolvem. ${ }^{2}$

Todas as partes do sistema interagem entre si continuamente para recriar o todo, e este por sua vez afeta o modo como as partes interagem. Exemplos de sistemas adaptativos complexos são o cérebro humano, cujos agentes são os neurônios; a mente humana, em que os símbolos e as imagens são os agentes; os seres humanos enquanto pertencentes a grupos e, por fim, as organizações humanas, que constituem sistemas sociais, econômicos e políticos complexos, os quais interagem entre si em diversos níveis - locais, nacionais e internacionais.

As interações que ocorrem entre os agentes podem conformar dois conjuntos distintos de ligações: a rede legítima e a rede "sombra". A rede legítima é formada tanto por regras formais como por informais, mas consistem em ligações que são entendidas e estabelecidas explicitamente entre os agentes.

2 Tradução livre da obra de Stacey, 1996. 
As relações no sistema legítimo são idealmente lineares, ou seja, bastante previsíveis, mas na prática muitas vezes acabam assumindo a forma de nãolinearidade.

A título de ilustração, pode-se pensar numa organização do tipo empresa. As ligações existentes seriam lineares se houvesse apenas uma única resposta para um dado número de alternativas - aquela, por exemplo, que maximizasse o lucro da empresa - e uma relação proporcional entre insumos e produtos, de modo que o todo fosse a soma das partes.

Já a rede "sombra" é constituída por ligações que surgem espontaneamente, não estabelecidas anteriormente, no processo de interação entre os agentes. São não-lineares, em geral, exatamente porque os indivíduos colocam em ação um conjunto de regras que não são nem implícita e nem explicitamente estabelecidas, surgindo diversas respostas para um mesmo conjunto de informações.

Em geral, assim, a rede legítima traz o sistema para uma maior estabilidade, enquanto o sistema "sombra" tende a desviá-lo da estabilidade.

A inter-relação desses dois conjuntos de ligações entre os agentes é fundamental para explicar como as transformações se processam no interior das organizações. Dentro desse esquema de ligações legítimas e "sombras", as organizações procuram sobreviver da melhor forma possível por meio de um processo de realimentação que passa por três fases: descoberta, escolha e ação.

A descoberta consiste na etapa de obtenção e processamento de informações, na qual cada agente procura levantar dados sobre os demais agentes do mesmo sistema ou dados sobre outros sistemas. No caso da empresa, por exemplo, cada indivíduo dessa organização interage com outros, em diversos níveis - dentro e fora da empresa - procurando obter informações sobre cada um deles. Com o conjunto de informações em mãos, os agentes passam para a segunda etapa, que consiste no processo de escolha da melhor opção. Por fim, a última etapa é a de implantação da estratégia escolhida que, por sua vez, vai influenciar a próxima fase da descoberta.

A descoberta, a escolha e a ação consistem, assim, em um processo de realimentação contínuo da organização, na qual cada fase coloca possibilidades e restrições para as demais. Durante esse processo, pode ocorrer aprendizado simples ou duplo. É denominado aprendizado simples quando o sistema se reproduz, sem introduzir mudanças em seus parâmetros gerais de controle. Qualquer desvio em relação ao esquema original é controlado de modo a trazer o sistema para a rota da estabilidade 
(ou do equilíbrio), prevalecendo o processo de realimentação negativo. Em geral, ocorre aprendizado simples quando a rede legítima, ou seja, as interações conhecidas e estabelecidas pelos indivíduos da organização, consegue manter o sistema estável, sem alterações. ${ }^{2}$

O aprendizado duplo, ao contrário, implica que o sistema altera os resultados de seu esquema, adaptando seu comportamento a um novo estímulo, de forma benéfica a ele. Neste caso, o processo de realimentação é positivo, normalmente acarretado pela prevalência da rede "sombra" existente na organização.

Pode-se depreender disso tudo, então, que o sistema só evolui quando há aprendizado duplo, ou seja, quando ele deixa de ser estável. No entanto, na região totalmente instável também não é possível haver aprendizado, uma vez que o sistema não dispõe de quaisquer mecanismos de controle. Portanto, só há aprendizado duplo na região denominada de limite do caos, a zona paradoxal em que há tanto estabilidade como instabilidade. Essa é uma região criativa, que proporciona evolução do sistema.

Organizações são sistemas dinâmicos complexos não-lineares que evoluem por meio do embate entre a rede legítima e a "sombra"; a primeira geralmente procurando trazer o sistema para a estabilidade, enquanto a segunda tentando introduzir elementos de instabilidade.

Quando o processo de realimentação positiva ocorre simultaneamente à realimentação negativa, sem que nenhum consiga prevalecer, o sistema encontra-se no limite do caos e torna-se criativo, na medida em que ocorre aprendizado duplo, gerando transformações qualitativas. Caso contrário, o sistema apenas se reproduz, não havendo alterações. Em sistemas complexos não-lineares, não há como fazer previsões de longo prazo, mas apenas conhecer o padrão geral pelo qual o sistema evolui, visto que na fase de limite do caos o sistema é hiper-sensível às condições iniciais.

O papel principal dos líderes de uma organização seria justamente o de conduzir o sistema para a região em que há criatividade, no limite do caos, em que a evolução é possível. No exemplo da empresa, os seus administradores deveriam deixá-la numa situação em que essa pudesse responder ativamente às estratégias de seus concorrentes. Para isso não poderia estar numa posição estritamente estável, ossificada, pois nesse caso não conseguiria se transformar e se manter competitiva. Também não poderiam seus administradores adotar estratégias que conduzissem a empresa ao caos completo, por exemplo, introduzindo modificações de forma tão rápida que não permitissem sua assimilação por parte dos funcionários.

2 No entanto, pode acontecer que a rede "sombra" seja a responsável pela manutenção da estabilidade, quando essa articula para que a rede legítima não implemente mudanças que gostaria de fazer. 
A arte de uma boa administração de qualquer organização, portanto, seria identificar a região intermediária - isto é, aquela que favorecesse a criatividade - e procurar conduzir a organização para esse estado.

\section{A complexidade no sistema empresarial}

A abordagem sistêmica das organizações fornece-nos uma base conceptual para entendermos as organizações. Estas são sistemas, compostas por subsistemas e integradas no macrossistema ambiental que as envolve. $\mathrm{O}$ seu comportamento é dinâmico, simplesmente porque evolui no tempo. Temos assim a empresa como sistema dinâmico. Resta saber se apresenta um comportamento que a possa qualificar como sistema dinâmico não linear e, logo, como objeto das teorias da complexidade que têm vindo a ser desenvolvidas.

Há duas propriedades fundamentais a observar, a auto-semelhança e a dependência sensível de pequenas causas, que resultam num comportamento imprevisível, turbulento e longe do equilíbrio. A auto-semelhança, no campo dos negócios, detecta-se pela observação de uma semelhança qualitativa de padrões de acontecimentos, dentro de limites reconhecíveis. Sem que isto resulte na possibilidade de previsão das respectivas conseqüências, significa apenas que se podem encontrar semelhanças qualitativas, em diferentes escalas, entre seqüências de eventos.

A segunda característica é mais relevante para este artigo. A dependência sensível de pequenas causas resulta da existência de mecanismos de feedback, que ampliam pequenas causas em ciclos viciosos ou virtuosos. Um erro aparentemente insignificante pode conduzir ao colapso de uma organização poderosa, tal como ao aproveitar uma oportunidade que parecia pouco auspiciosa outra empresa pode ser conduzida a um sucesso exponencial.

A Kodak, após a Segunda Guerra Mundial, negligenciou voluntariamente o mercado japonês, por considerá-lo pouco importante. Isso abriu caminho para que a Fuji conseguisse uma sólida quota de $70 \%$ do seu mercado interno e partisse daí para desafiar seriamente a Kodak no resto do mundo, obrigando esta a implementar reduções de custos de emergência e levando o valor das suas ações a descer. Tratou-se claramente de uma situação na qual uma pequena causa se ampliou, com conseqüências desastrosas (para a Kodak) ao fim de algum tempo.

Outro exemplo deste tipo de comportamento é o caso da Netscape. A World Wide Web foi desenvolvida entre 1989 e 1991 pelo cientista britânico Timothy Berners-Lee, como uma parte da rede mundial Internet, na qual se poderia aceder a documentos em hipertexto, integrando texto e imagens e 
possibilitando a ligação a outros documentos mediante a simples seleção (geralmente com o rato) de uma palavra sublinhada. Foi a WWW que levou à crescente popularidade da Internet e a sua recente globalização. Para 'navegar' na Web, é necessário um programa denominado browser, que lê os documentos em hipertexto e gere as complexas ligações com os servidores onde estes estão disponíveis. A Netscape, de Marc Andreesson, criou precisamente um browser espantoso, o Netscape Navigator, que revolucionou a maneira de ver a World Wide Web e contribuiu para a sua expansão. Quanto mais utilizadores a Web tivesse, mais clientes potenciais a Netscape tinha para o seu Navigator e mais páginas surgiriam, aumentando o interesse do público e atraindo novos utilizadores. Apanhada no meio deste ciclo virtuoso, a Netscape ganhou em muito pouco tempo uma relevância e prosperidade notáveis, dominando um mercado ao qual a própria Microsoft chegou atrasada.

Naturalmente, existirão organizações que, devido à sua dimensão reduzida e a uma rara estabilidade do contexto onde se inserem, não apresentarão comportamentos complexos e longe do equilíbrio. Para estas, as conclusões deste contributo não terão o mesmo interesse, mas as empresas nesta situação são cada vez em menor número. A complexidade no comportamento de uma organização pode resultar de si própria, pela sua dimensão ou pela forma como os seus subsistemas interagem em feedback, mas pode também ser resultante da turbulência do ambiente de mercado onde esta se insere e dos mecanismos que lhe estão subjacentes.

Entenda-se então a empresa (com as restrições referidas acima) como um sistema dinâmico não linear. Qual será a relevância prática desta concepção? Simplesmente brutal. As decisões que tomamos dependem grandemente do quadro mental que construímos para interpretar a realidade. Se alterarmos esse quadro mental, estaremos também a modificar a forma como tomamos decisões e, em última análise, o nosso comportamento. É deste ponto de vista que o contributo das teorias da complexidade pode ser extremamente importante para a Teoria da Gestão. É óbvio que quem procure na estabilidade e equilibrio o sucesso, terá poucas probabilidades de encontrar se este estiver longe do equilibrio, algures nas correntes do Caos. Adaptando um modelo mental mais adequado à realidade atual, estaremos necessariamente a caminhar na direção certa.

Mas este novo modelo que agora se propõe não faz sentir o seu impacto de igual forma em todas as dimensões da organização. Quando se tratar de um processo de mudança fechada em curto prazo, os métodos tradicionais de controle continuam, naturalmente, a aplicar-se. O principal reflexo vai-se fazer sentir, naturalmente, nas situações de final aberto, de dimensão estratégica, que determinam o futuro da organização. A Gestão Estratégica é, por isso, o primeiro alvo de uma Gestão consciente da complexidade imprevisível. 


\section{Da emergência da estratégia a uma nova gestão das organizações}

Considerar a empresa como um sistema dinâmico não linear altera, como já vimos, o quadro mental em que esta deve ser entendida. Desta alteração devem resultar conseqüências práticas na utilização que os gestores fazem do seu poder dentro da organização.

Em primeiro lugar, o longo prazo tem que ser encarado com a maior atenção, mas não por meio de planos ou confiando em visões. Um futuro desconhecido e (o que é mais importante) impossível de conhecer é construído a cada momento. Sendo assim, a empresa confrontar-se-á permanentemente com questões com potencial estratégico, ou seja, que podem vir a contribuir para a construção do seu futuro. Este potencial estratégico pode não ser aparente, pois, como já vimos, pequenas causas podem provocar grandes efeitos. Por isso, é necessária grande atenção e constante reavaliação para detectar o maior número de questões com esta importância.

A criação de uma saudável cultura de empresa não pode degenerar na constituição de uma legião acrítica de fanáticos. A heterogeneidade é a chave da criatividade e uma organização que saiba aproveitar as diferenças de opinião e de valores entre os seus elementos para explorar novas idéias e inovar estará um passo à frente das suas concorrentes.

Por último, é preciso que a empresa saiba utilizar, em simultâneo, diferentes formas de controle para diferentes situações. O controle operacional de curto prazo, baseado em processos de planificação, deverá, naturalmente, continuar a assegurar a gestão corrente da empresa. A inovação deverá ser introduzida no controle das questões com potencial estratégico, onde é necessário o desenvolvimento de novos modelos.

A mudança com que uma organização se confronta pode variar desde a mudança fechada, na qual as conseqüências são conhecidas, até a mudança aberta, cujo desfecho é incognoscível. Se na primeira situação era possível definir a priori uma intenção e executá-la, próximos do outro extremo não faz sentido definir orientações, pois a estratégia vai ser construída ao longo do percurso. No primeiro caso, falava-se em formulação da estratégia, no segundo é mais correto referir-se um processo de formação da estratégia (KEGAN; LAHEY, 2000, p. 56) afirmam:

Se queremos entender o desenvolvimento da mudança, devemos prestar mais atenção às nossas poderosas inclinações para não mudar. Essa atenção nos ajudará a descobrir dentro de nós mesmos a força e a beleza de um sistema imunológico oculto, o processo dinâmico por meio do qual tendemos a impedir a mudança, por meio do qual fabricamos continuamente os antígenos da mudança. Se conseguirmos destravar esse sistema, liberaremos novas energias para apoiar as novas formas de ver e de ser. 
A estratégia forma-se como o padrão que emerge de um conjunto de ações isoladas, que se reforçaram ou anularam, e que só é verdadeiramente visível retrospectivamente. É assim por meio de um processo de construção que a estratégia surge.

O controle tradicional baseia-se na definição prévia da intenção, incidindo sobre a sua concretização. Não existindo esta definição, as preocupações-chave da gestão devem ser criar condições para gerar criatividade e inovação e encontrar novas formas de controlar estrategicamente a organização.

Em mudança aberta, face à impossibilidade de prever, os gestores de uma empresa podem considerar que toda a inovação é um acréscimo de risco, adotando uma postura radicalmente conservadora. Esta é a conduta mais perigosa, pois torna apenas numa questão de tempo saber quando essa empresa vai ser liquidada por inúmeros concorrentes mais inovadores. Por outro lado, o raciocínio contrário de que para maximizar a inovação se devem permitir todas as experiências, pode redundar numa anarquia autodestrutiva. Resta então à empresa um estreito caminho, entre estes dois precipícios, no qual se deve equilibrar, aprendendo com os erros e inovando tanto quanto possível, sem comprometer a sua integridade.

A forma mais promissora de criar condições para que a criatividade possa surgir é por meio de um processo de aprendizagem de grupo, sem limitações formais ou de estrutura. Contudo, para evitar que a organização caia na anarquia destrutiva, a estrutura hierárquica deve constituir um referencial de distribuição de poder regulador. Uma forma de compatibilizar esta estrutura com a aprendizagem de grupo é pela constituição de equipes heterogêneas para explorar novas perspectivas sobre problemas ambíguos de potencial estratégico.

Estas equipes devem reunir pessoas de diferentes áreas e níveis hierárquicos, de forma a garantir uma tensão criadora resultante da troca de pontos de vista diferentes, para a qual é fundamental assegurar uma total liberdade de expressão. Competirá aos gestores, pelo seu comportamento e pela forma como utilizam o seu poder, criar as condições para que eles próprios e os seus colegas possam aprender em grupo sobre a mudança aberta.

Esta aprendizagem de grupo deve ser incentivada e aperfeiçoada, de forma a que a empresa esteja preparada para desenvolver novos modelos mentais para as novas situações com que se defronte. No entanto, é fundamental ter presente que não se pode forçar o surgimento de uma idéia criativa. O que pode ser feito é aumentar as probabilidades de que isso aconteça.

Face à mudança aberta, a capacidade de aprendizagem complexa em grupo é fundamental e depende dela a escolha estratégica inovadora e criativa. 


\section{Novas formas de controle e pilotagem das organizações}

Ao lidar em simultâneo com um leque de diferentes níveis de mudança (desde a mudança fechada até a aberta) a empresa deve saber aplicar, simultaneamente, sistemas de controle diferenciados. Para as conseqüências a curto prazo da mudança fechada, já vimos que o sistema convencional de controle de gestão se adapta perfeitamente, devendo a empresa utilizar o planejamento e a análise de desvios. É para enfrentar a mudança aberta que é necessário o desenvolvimento de novos modelos de controle, que consigam direcionar a dinâmica criativa da empresa no sentido do êxito.

Não é demais repetir que em gestão não há receitas. Na gestão em mudança aberta, menos se poderia aceitar a prescrição de modelos ou técnicas concretas. Ter presentes estes pressupostos é importante para enquadrar o que se segue como meras sugestões ilustrativas das possibilidades que a gestão em complexidade oferece.

O controle em mudança aberta deve ser concebido como um processo contínuo e qualitativo, por oposição ao controle periódico e quantitativo inerente à gestão estratégica tradicional. Este novo tipo de controle deve incidir sobre o processo de formação da estratégia e não sobre o resultado desse processo. Deve, por isso, agir sobre os mecanismos de tomada de decisão e sobre o desenvolvimento da capacidade de aprender.

A capacidade fundamental da gestão deverá ser detectar e dar atenção às questões com potencial estratégico que se colocam à empresa. Para isso, deve ter em atenção a dinâmica de auto-reforço (que faz com que pequenas causas possam ter grandes conseqüências), que pode "mascarar" o que vai determinar o futuro da empresa, fazendo-o parecer insignificante.

A chave para este controle pela atenção pode estar na utilização e permanente atualização de uma agenda de questões com potencial estratégico. A construção desta agenda deve estar intimamente ligada ao processo de aprendizagem complexa e deve orientar a escolha das ações exploratórias a empreender. A sua importância será tanto maior quanto mais a empresa, como grupo de pessoas, conseguir aprender da sua atualização e quanto maior for a atenção que a gestão de topo lhe dedicar.

Para além de depender das agendas estratégicas, as decisões "criativas" devem também depender de um processo político de decisão. Este processo pode definir-se de forma tão simples como uma idéia, para ser posta em prática, necessita de apoio. Este controle introduz uma componente de autoregulação no sistema, tornando participada a escolha estratégica e aproveitando o bom senso coletivo para orientar essa escolha.

Quer com a interpretação da mudança interna e externa, quer com este processo de tentativa e erro, a organização deverá ser capaz de aprender, 
constituindo essa aprendizagem um referencial para a própria construção da agenda estratégica.

Este é um modelo possível para a pilotagem de organizações longe do equilíbrio. Não se procura aqui uma harmonia interna e uma adaptação perfeita, mas sim uma dinâmica constante de criação e aprendizagem, que leve os gestores a desenvolver novos modelos para lidar com cada nova situação.

É na capacidade de inovação constante que se joga, verdadeiramente, o futuro e a sobrevivência de cada empresa. Ignorar este desafio é o caminho mais seguro para a própria destruição.

\section{Adaptando-se às condições dinâmicas}

Se os teóricos da complexidade estão certos, algumas das máximas mais queridas dos administradores necessitam ser revistas.

As doutrinas convencionais dizem que a administração é uma atividade de feedback negativo - fixa uma estratégia e leva a empresa na direção correta pela correção de seus desvios do plano traçado. À luz da complexidade, o quadro é mais complicado.

A teoria convencional está correta para as atividades do dia-a-dia rotinas ou fabricação de componentes padrões. Mas para as atividades criativas, como a fixação de estratégias de longo prazo, ela é perigosa.

Os resultados não desejados das ações não podem ser implantados porque a estrutura do sistema torna o futuro impossível de ser conhecido. O corolário é que a estratégia viável não é algo que é o resultado de um intento prévio de um líder visionário. Em vez disso, ela emerge das múltiplas possibilidades lançadas por várias dinâmicas de grupo da organização em colisão com o ambiente.

De acordo com isso, diz Stacey (1994), os gerentes deveriam se pensar como jardineiros em vez de executivos - em vez de intencionarem, eles deveriam deixar acontecer.

Na literatura da administração, os executivos controlam as companhias por meio de estruturas e procedimentos ordenados. Se isso é tudo o que eles fazem em um complexo mundo, a companhia está destinada a seguir o caminho do Tyrannosaurus rex.

A tentativa de fazer o sistema estável trabalha apenas para torná-lo incapaz de interagir com o meio para criar uma alternativa futura. Resultado: estagnação e morte.

Os consultores enfatizam que culturas e valores fortemente compartilhados são essenciais para conduzir a companhia ao futuro. Em condições dinâmicas, onde o futuro consiste de múltiplas e variadas agendas, a administração monolítica provavelmente falhará na geração da criatividade 
necessária para dotar a companhia de adequadas opções à frente. Por isso, a diversidade de opiniões e abordagens é importante.

O pensamento único que não comporta diferentes visões pode ter sido um dos mais cruciais fatores para a queda de tantas "excelentes" firmas na turbulenta década passada.

Muitos estrategistas acreditam que o sucesso é o resultado da manutenção de um equilíbrio adaptativo com o ambiente. Se isso fosse verdade, a liberdade de administrar seria reduzida à escolha da adaptação certa ou errada. No mundo da complexidade, os riscos são muito maiores. Primeiro porque equilỉbrio significa morte. Segundo porque em condições não-estáveis e evolutivas, o ambiente também se adapta à companhia tanto quanto esta a ele. As implicações disto significam que a companhia não pode culpar o ambiente por suas falhas a empresa bem-sucedida é vertiginosamente livre para criar seu próprio futuro.

O conhecimento científico, como hoje é concebido, foi construído progressivamente desde o século XVI. Os cientistas mais influentes nesta construção, como Newton, Darwin, Durkheim, Lavoisier ou Adam Smith, trabalharam e viveram entre o século XVIII e o início deste século. Dos seus trabalhos resultou o paradigma científico dominante, que procura um conhecimento objetivo, universal e determinista.

Este modelo de racionalidade foi desenvolvido essencialmente no seio das ciências naturais, com base em regras metodológicas e princípios epistemológicos perfeitamente definidos, com base nos quais define mesmo o caráter racional de uma forma de conhecimento. A sua característica mais marcante é uma confiança quase absoluta na capacidade de previsão da ciência, que resulta na convicção de que a explicação e previsão de todos os fenômenos está ao seu alcance. A matemática, com as suas idéias claras e objetivas, constituise assim não só como o principal instrumento deste paradigma científico, mas também como o seu próprio suporte lógico.

Apesar do seu sucesso (patente na sua aplicação tecnológica corrente), este paradigma parece estar hoje a ser posto em causa. A sua crise iniciou-se com a Teoria da Relatividade de Einstein e a mecânica quântica, não sendo possível ainda saber quando se conhecerá o seu desfecho.

Segundo Santos (1991), os sinais conhecidos nos permitem tão-só especular acerca do paradigma que emergirá deste período revolucionário, mas que, desde já, pode-se afirmar com segurança que colapsarão as distinções básicas em que assenta o paradigma dominante.

Este colapso do paradigma dominante resulta de um conjunto de novos conhecimentos científicos, dos quais se podem destacar quatro descobertas fundamentais: a Relatividade da Simultaneidade de Einstein, o Princípio da Incerteza de Heisenberg, o Teorema da Incompletude de Gödel e a nova abordagem da complexidade em sistemas dinâmicos. 
O pensamento sobre a Relatividade da Simultaneidade de Einstein é tão simples como isso: como a simultaneidade de acontecimentos distantes não pode ser demonstrada, só pode ser definida, portanto é arbitrária. Isto é o suficiente para alterar por completo a nossa noção de tempo e espaço, deitando por terra o tempo e espaço absolutos de Newton.

O Princípio da Incerteza de Heisenberg, no âmbito da mecânica quântica, tem também conseqüências marcantes ao resultar da demonstração de que não é possível conhecer simultaneamente a posição e a velocidade de uma partícula atômica. Ou seja, que não é possível observar sem alterar o objeto observado.

Os teoremas de Gödel são, talvez, a mais surpreendente destas descobertas, pois surgiram no domínio científico que mais imune parecia estar a abalos epistemológicos - a Matemática. Gödel demonstrou que é possível formular proposições que não se podem demonstrar nem refutar seguindo as regras da lógica matemática.

O quarto pilar desta crise do paradigma dominante é a nova abordagem da complexidade em sistemas dinâmicos. Trata-se de um novo corpo de conhecimentos cujo objeto são os sistemas dinâmicos não-lineares, logo, de comportamento imprevisível, que atravessa disciplinas tradicionais e contraria o mecanicismo clássico com conceitos como a auto-semelhança ou a dependência sensível das condições iniciais.

A crise do paradigma dominante está assim a destruir, progressivamente, as fronteiras disciplinares em que, arbitrariamente, a Ciência tinha dividido a realidade. A ciência determinista está a ser substituída por uma ciência probabilística.

Quanto à caracterização do paradigma emergente, esta só pode ser antecipada especulando sobre o que se pode depreender da crise do paradigma dominante.

Em primeiro lugar, a fragmentação do conhecimento na pósmodernidade parece ser temática e não disciplinar, ou seja, todo o conhecimento é local e total. Isto leva a que, na práxis interveniente, seja recomendável pensar globalmente para agir localmente.

Por outro lado, afirma Santos (1991), composição transdisciplinar e individualizada sugere um movimento no sentido da maior personalização do trabalho científico, ou seja, a dimensão subjetiva, tão arduamente combatida pelo paradigma dominante, ganha agora uma nova importância fundamental. Santos (1991) afirma que todo o conhecimento é autoconhecimento.

Por fim, é de referir a tendência para que todo o conhecimento científico se constitua em senso comum. A Ciência pós-moderna, ao saber que nenhuma forma de conhecimento é racional em si mesma, procura a 
racionalidade pelo diálogo com outras formas de conhecimento, pois "só a configuração de todas elas é racional".

Numa inversão completa dos papéis definidos pelo paradigma dominante, agora é o senso comum que se considera a forma de conhecimento mais importante, pois é ele que, no cotidiano, orienta as nossas ações e a nossa compreensão da realidade.

O conhecimento em gestão de empresas pode ser apontado como um bom exemplo deste novo tipo de construção de saber. Resulta de uma dialética permanente entre sua prática interveniente e o referencial teórico que a enquadra. Como veremos, é este o motor da sua evolução e a fonte do seu desenvolvimento.

\section{A necessidade de um novo modelo mental}

Para lidar com a enorme quantidade de informação com que é constantemente bombardeado, o cérebro humano recorre a modelos mentais, selecionando e simplificando a informação em padrões causais reconhecíveis. São estes modelos que depois utiliza para enquadrar a nova informação que recebe e para determinar as suas reações.

É assim que as nossas escolhas e ações dependem daquilo que aprendemos, pelo que quanto mais adequados à realidade estiverem os nossos modelos mentais, mais eficazes serão as nossas ações. É por isso que a abordagem largamente aceite para a gestão estratégica deve ser substituída: porque constrói um modelo mental que não corresponde à realidade.

Os atuais modelos de gestão estratégica assentam, como vimos no capítulo anterior, em visões e valores partilhados, num processo de planejamento formalizado e num controle corretivo intermitente.

Estas bases partem do modelo mental tradicional do funcionamento de uma empresa: um sistema aberto, mas em que se podem observar as relações diretas entre causas e efeito, para o qual o êxito será encontrado no equilíbrio estável, com harmonia interna e uma adaptação perfeita ao meio. Pressupõese assim que as previsões do futuro não só são possíveis como devem estar na base de um processo reativo ou proativo de adaptação.

É aqui que se situa, precisamente, a falha de toda esta construção teórica. Este modelo ignora a dinâmica de feedback que faz com que pequenas causas originem grandes efeitos, ignora que a turbulência torna o futuro, por definição, incognoscível e impossível de antecipar e não aceita que cada empresa, como ator organizacional, pode determinar e influenciar as características do próprio meio. 
A abordagem convencional da gestão estratégica não considera, por isso, a importância da aprendizagem complexa e insiste na definição de planos que, passado muito pouco tempo, encontram-se desatualizados e não são executados.

Uma vez que a natureza do cérebro humano faz com que seja impossível agir sem que se tenha presente um modelo mental, importa que este modelo retenha as características fundamentais da realidade. É por isso que é necessário um novo quadro mental para a gestão estratégica, porque mudando os modelos, muda-se, indireta, mas profundamente, todo o padrão de ações.

As antevisões do estado futuro da empresa, a Visão ou Missão estratégica, tendem a ser mais prejudiciais do que benéficas. Apesar dos exemplos que são freqüentemente citados na literatura de gestão (como a missão da Microsoft de "colocar um computador em cada lar, cada secretária") parecem ser mais numerosos os casos em que uma "visão" enganadora se revelou uma miragem, tendo a empresa persistido num caminho errado, por vezes à custa da própria sobrevivência.

Por outro lado, as missões ou visões expressam apenas, na maior parte dos casos, condições básicas de sobrevivência empresarial (do tipo "servir os nossos clientes" ou "prestar o melhor serviço possível") ou então se limitam a enunciar aspirações comuns, à partida, a todas as organizações econômicas (por exemplo "liderar o mercado", "prestar o melhor serviço" ou "ter a maior rendibilidade"). Em qualquer destas situações, partir de uma idéia preconcebida do futuro não propicia que se aproveitem as oportunidades que surjam, nem sugere que a orientação estratégica se ajuste às alterações da realidade. Partir de visões para construir a estratégia é assim definir o caminho antes de se conhecer o mapa.

A coesão interna e a partilha de valores são também considerados fundamentais pela abordagem convencional da gestão estratégica. Contudo, não é pela unanimidade e homogeneidade que se obtém a necessária criatividade para agir no atual contexto empresarial. Estes valores contribuem para uma cultura de empresa conservadora, criando resistências ao surgimento e, sobretudo, à aceitação de idéias novas.

O planejamento estratégico surgiu associado ao maior período de crescimento contínuo deste século, em meados dos anos 60. A mudança que as empresas enfrentavam na altura tinha, por isso, características de mudança quase fechada, o que fazia com que a projeção do comportamento passado numa previsão do futuro fosse, em princípio, útil.

O planejamento estratégico tem em comum com a Organização Científica do Trabalho de Taylor uma separação entre a decisão e a execução, a teoria e a prática. 
O planejamento procurou assim formalizar o processo intelectual de criar estratégia. Seu objetivo é que os planejadores formulem as melhores estratégias e os planos detalhados para executá-las. Se os resultados não corresponderem ao pretendido, haverá sempre duas razões perfeitas (para os planejadores): ou os planos foram executados de forma deficiente ou os gestores de topo não os apoiaram devidamente. O problema, contudo, é mais profundo.

A estratégia, como já foi definida neste trabalho, resulta essencialmente da síntese de inúmeras variáveis e tendências, para a qual são fundamentais a intuição e a criatividade. O planejamento é um processo analítico, sendo por natureza incapaz de produzir um resultado de síntese. O planejamento estratégico não pode ser, por isso, confundido com pensamento estratégico.

$\mathrm{Na}$ realidade, o processo de planejamento é, com freqüência, um elemento conservador na organização, apesar do seu propósito manifesto de "facilitar as mudanças".

Os planos são construções tão detalhadas que se tornam frágeis, podendo cair por terra ao mínimo ajustamento. As próprias características de formalismo do processo tornam-no centralizado e desincentivam a iniciativa e a criatividade. Em resultado, o planejamento geralmente limita-se a articular e reorganizar a linha estratégica atual, sem suscitar grandes mudanças organizacionais e sem criar, na realidade, estratégia.

Por último, em relação ao processo de planejamento, os seus métodos de previsão não passam de projeções do passado sobre o futuro, pelo que são incapazes de levar em conta as descontinuidades e os efeitos da turbulência sobre a possibilidade de prever o futuro.

O controle intermitente, a intervalos de tempo determinados e essencialmente quantitativo, permite verificar e corrigir desvios quantitativos face ao que tinha sido planejado. É assim apenas um controle da execução e não um controle com resultados na estratégia da organização.

Apesar de os próprios gestores não seguirem o modelo formalizado que eles próprios preconizam, há uma enorme resistência a mudar o quadro mental e a ilusão de segurança e estabilidade que o planejamento implica. Aceitar que o futuro é desconhecido e, sobretudo, imprevisível, podendo a sobrevivência da empresa depender de cada pequena ação é, para dizer o mínimo, motivo de ansiedade para a maior parte dos gestores.

\section{Conclusões}

Acredita-se que a teoria da complexidade aplicada às organizações, resumida acima, possa ser aplicada também para estudar todos os tipos de organizações. 
Até agora, a história da administração pode ser vista como uma constante luta pela ordem, pelo controle e pela previsibilidade. As políticas atuais de valorização do indivíduo e planificação das organizações não fogem desse modelo. O objetivo ainda é o de proceder da mesma forma: sair do $a$ e chegar ao $b$ da visão estratégica da companhia. A diferença é que hoje em dia se assumiu que uma melhor maneira de fazer isso é dar maior liberdade para que os vários grupos dentro das empresas tomem suas próprias decisões, em vez do uso puro e simples de comandos e controles diretos.

A implicação desorientadora da complexidade, no entanto, é a de mostrar que não há caminho certo para chegar a $b$. A complexidade afirma que os resultados de longo prazo para entidades complexas como empresas, mercados ou economias não são passíveis de serem conhecidos. Isso porque as relações entre as ações e seus resultados são não-lineares; por meio de intricados feedbacks, as causas podem se transformar em efeitos e os efeitos em causas, de maneira que, na prática, ligações causais não podem ser traçadas. E dependendo das condições iniciais, variações aparentemente insignificantes podem ser amplificadas até produzirem surpreendentes conseqüências.

Os sistemas puramente físicos ou químicos são determinísticos - as regras são as mesmas, mesmo se os resultados reais não puderem ser previstos. Mas sistemas orgânicos complexos como o das espécies, ecológicos ou sociedades são adaptativos em vez de determinísticos, de modo que as regras mudam à luz das conseqüências do comportamento que elas mesmas produzem. Elas evoluem freqüentemente em inesperadas direções, até o ponto em que um novo conjunto de regras torna-se aplicável.

A sociedade moderna caracteriza-se por uma abundância de informação, associada à sua globalização, num quadro de mudança permanente, imprevisível e turbulenta. São tempos loucos, que fazem novas exigências às organizações e as confrontam com novos desafios.

O conhecimento científico também está a sofrer uma alteração profunda, com a progressiva substituição do determinismo clássico por um paradigma emergente, que tem como arautos a teoria da relatividade, a mecânica quântica e, mais recentemente, a chamada teoria do caos, uma nova abordagem científica da complexidade em sistemas dinâmicos.

A gestão enquadra a sua prática interveniente num referencial teórico que tem vindo a ser desenvolvido ao longo deste século, adaptando-se continuamente de forma a responder às principais preocupações dos gestores em cada momento. Hoje em dia, a questão que mais inquietação desperta nos gestores é a mudança e o seu impacto organizacional

As empresas são sistemas abertos, em interação permanente com meio onde se inserem. Este conceito foi introduzido pela abordagem sistêmica 
da gestão de empresas, e é hoje aceite pacificamente. A novidade é a noção de que nessa interação os sistemas-empresa apresentam um comportamento dinâmico, quer no seu interior, quer na relação com o meio, estabelecendo-se ciclos auto-reforçados, que fazem com que pequenas causas originem efeitos mais do que proporcionais e seja impossível a previsão ou antecipação do futuro.

A empresa, como sistema, enquadra-se assim no objeto da nova abordagem científica da complexidade, podendo ser qualificada como sistema dinâmico não linear. O seu comportamento corresponde às principais características destes sistemas: é impossível de prever e está sujeito a ciclos auto-reforçados, com dependência sensível de pequenas causas.

As conseqüências desta alteração no enquadramento do conceito de empresa fazem-se sentir, em primeiro lugar, no domínio da gestão que lida com a forma e posicionamento da empresa no longo-prazo: a gestão estratégica.

A abordagem convencional da gestão estratégica assenta sobre os conceitos de missão, planejamento e controle e vê a criação de estratégia como um processo formal e analítico. Está inerente a esta abordagem a convicção de que o êxito será encontrado na harmonia interna e na adaptação perfeita ao meio.

A estratégia resulta da síntese de um conjunto vasto de tendências e ações, pelo que um processo analítico como o planejamento parece inadequado para a sua criação. Por outro lado, o caráter formal e detalhado da sua formulação desencoraja a verdadeira mudança organizacional.

Os modelos mentais estão na base da nossa compreensão da realidade e determinam o padrão das nossas ações. Assim, mudando o quadro mental, alterar-se-á, necessariamente, a forma como se intervém sobre a realidade. É desta mudança de quadro mental que deverá partir o principal impacto da nova abordagem científica da complexidade sobre a gestão de empresas em geral e a sua gestão estratégica em particular. Se o modelo da empresa como sistema dinâmico não linear que opera sempre longe do equilíbrio corresponde melhor à realidade, este será necessariamente mais útil e a sua adaptação aumentará a probabilidade de que as escolhas estratégicas sejam acertadas.

Este novo modelo implica o abandono da perspectiva atual sobre a gestão a longo prazo como um processo de planejamento. No entanto, está longe de sugerir o abandono do longo prazo, implica até que este seja considerado com maior atenção.

A formação da estratégia é, neste quadro, caracterizada como um processo no qual a orientação estratégica emerge, em resultado de um padrão de ações e condicionantes que só é visível retrospectivamente. Esta característica não impede que se identifiquem os fatores críticos de sucesso e se possam sugerir algumas medidas para uma gestão estratégica eficaz em turbulência. 
Neste sentido, a preocupação fundamental da gestão estratégica deverá ser permitir que as novas orientações estratégicas surjam. Para isso, é necessário criar condições que propiciem a criatividade e a inovação, utilizando a aprendizagem complexa de grupo como o método fundamental para que isso aconteça.

De forma a aproveitar essa dinâmica organizacional, os gestores de topo da organização deverão saber aplicar novas formas de controle para gerir o longo prazo, centradas na aprendizagem complexa e no processo político de tomada de decisão (fazendo depender, por exemplo, o explorar de um novo caminho de negócio do apoio que a idéia obtenha dentro da organização). Contudo, para enfrentar a mudança fechada do curto prazo, a empresa deverá manter um sistema de controle convencional, quantitativo e que envolva um processo de planejamento, de forma garantir a gestão corrente e manter a integridade da organização.

Assim, uma gestão eficaz do processo estratégico em turbulência deverá ser capaz de aplicar, em simultâneo, diferentes formas de controle, em função da natureza da mudança.

\section{Referências}

KEGAN, R. L.; LAHEY, L. How the way we talk can change the way we work: Seven Languages for Transformation. Chicago: Jossey-Bass, 2000.

KUHN, Thomas. Estrutura das revoluções científicas. Chicago: University Chicago, 1970.

MORIN, E. La méthode 2: La vie de la vié. Paris: Suil, 1980.

PRIGOGINE, Lya. O fim das certezas: tempo, caos e as leis da natureza. São Paulo: Universidade Estadual Paulista, 1996.

SANTOS, Boaventura de Sousa. Um discurso sobre as ciências. Porto: Afrontamento, 1991.

STACEY, Ralph. A gestão do caos. São Paulo: Dom Quixote, 1994.

Complexity and creativity in organizations. San Francisco: BerrettKoehler, 1996.

Recebido: 17 de abril de 2007

Aceito: 17 de agosto de 2007 